\title{
TRADISI SEREN TAUN GURU BUMI DI SINDANG BARANG \\ KABUPATEN BOGOR \\ (Kajian Semiotik)
}

\author{
Tati Suryati \\ MGMP Bahasa Sunda Kabupaten Bogor \\ Pos-el: tatisuryati789@gmail.com
}

\begin{abstract}
Abstrak
Penelitian ini bertujuan untuk mendeskripsikan: (1) bentuk dan pelaksanaan tradisi Seren Taun Guru Bumi; serta (2) unsur semiotik yang terdapat dalam tradisi Seren Taun Guru Bumi. Untuk membahas persoalan tersebut, penelitian ini mengggunakan pendekatan semiotik, dengan metode deskriptif analitik. Sedangkan teknik penelitian yang digunakan adalah teknik studi pustaka. Hasilnya: (1) Seren Taun Guru Bumi dilaksanakan setiap tahun sekali pada bula Muharam. Tradisi ini terdiri dari sembilan kagiatan yang harus dilaksanakan selama seminggu. Kegiatan tersebut adalah; sedekah ngadiukkeun, ngembang makam karuhun, tadisi sudat, tradisi munday atau marak, ngala cai kukulu, ngahijikeun cai kukulu, sedekah kuéh, nugel munding, dan helaran dongdang; serta (2) ikon yang terdapat dari tradisi tersebut adalah padi, bunga, air, ikan, kerbau, dan dongdang; indéks yang terdapat dalam tradisi ini tertuang dalam nama tradisinya yaitu sérén taun, sedekah ngadiukkeun, ngembang makam karuhun, ngala cai kukulu, ngahijikeun cai kukulu, sedekah kuéh, munday, nugel munding dan helaran dongdang; (c) simbol yang terdapat dalam tradisi ini di antaranya adalah padi simbol dari kemakmuran, air kukulu dan air tujuh rupa simbol dari kehirupan, bunga tujuh rupa simbol dari kehirupan dan harapan, kue tujuh rupa simbol dari silaturahmi, bakak ayam simbol dari kepasrahan, menyan simbol dari isi hati, parukuyan dan buyung simbol dari raga, dongdang simbol dari segala nikmat yang harus dijaga, berburu ikan simbol dari kesamaan identitas, kerbau simbol dari dunia langit, dan majikeun paré simbol dari menikahkan padi agar hasil benihnya bagus.
\end{abstract}

Kata kunci: seren taun, semiotik, pembelajaran membaca.

\section{TRADITION OF SEREN TAUN GURU BUMI IN SINDANG BARANG DISTRICTS BOGOR AS LEARNING MATERIALS ABILITY TO READ CULTURE IN A HIGH SCHOOL (Semiotic Study)}

\begin{abstract}
This study aims to describe: (1) the form and implementation of the Seren tradition of the Earth Teachers; and (2) semiotic elements contained in the Seren tradition of the Teachers of the Earth. To discuss this issue, this study uses a semiotic approach, with descriptive analytical methods. While the research technique used is a library study technique. The result: (1) Seren The Earth Teachers are held once a year in the Muharam bull. This tradition consists of nine activities that must be carried out during the week. These activities are; almsgiving, the burial of karuhun, the tadisi sudat, the tradition of munday or rampant, ngala cai kukulu, ngahijikeun cai kukulu, sedekah kuéh, nugel munding, and helaran dongdang; and (2) the icons contained in the tradition are rice, flowers, water, fish, buffalo and dongdang; the indes contained in this tradition are contained in the name of the tradition, namely sérén taun, sedekah ngadiukkeun, karamun burial tombs, ngala cai kukulu, ngahijikeun cai kukulu, kuek haha, munday, nugel munding
\end{abstract}


and helaran dongdang; (c) the symbols contained in this tradition include rice symbol of prosperity, kukulu water and seven forms of inhaled water symbol, seven forms of symbol of inhale and hope, seven forms of symbols from hospitality, chicken bakak symbol of submission, menyan symbol of the contents of the heart, parukuyan and pitcher symbol of the body, the symbol of all the blessings that must be guarded, hunting the symbolic fish of the same identity, the symbol of the buffalo of the celestial world, and the symbolic symbol of marrying the rice so that the seed yield is good.

Keyword: seren taun, semiotic, reading learning.

\section{PENDAHULUAN}

Hakikatnya kebudayaan merupakan cara berfikir untuk mempertahankan hidup. Sedangkan proses berkembangnya fikiran manusia dipengaruhi oleh keadaan alam dan sosial yang ada dilingkungan tempat tinggal. Berkaitan dengan itu, sudah tentu setiap suku bangsa, bahkan setiap daerah memiliki produk kebudayaan masing-masing. Hal tersebut bisa dilihat dari kesenian, bahasa, sastra, dan adat-istiadat yang terdapat di daerah tersebut.

Kata kebudayaan sendiri berasal dari kata buddhayah yang berarti budi atau akal. Dalam bahasa Inggris kata budaya berasal dari bahasa Latin yaitu colere yang memiliki arti mengolah tanah atau bercocok tanam atau bisa diartikan segala usaha manusia untuk mengolah alam. Kebudayaan juga bisa diartikan semua pengetahuan dan pengalaman manusia yang digunakan untuk menginterpretasi lingkungan sekitar dalam mempertahankan hidupnya. Dalam hal ini kebudayaan merupakan mekanisme kontrol manusia dalam berlaku dan bertindak (Koentjaraningrat, 1985, kc. 9).

Setiap budaya yang lahir di masyarakat tentu harus dijaga, bahkan perlu diwariskan ke setiap generasi selanjutnya. Hal ini dilakukan agar produk budaya yang lahir bisa tetap hidup dan menjadi ciri khas masyarakat tersebut. Adapun proses pewarisan sehingga menjadi ciri khas masyarakat selanjutnya bisa disebut tradisi. Hal ini sejalan dengan pendapat Danadibrta (2006, hal. 655), yang menyebutkan bahwa tradisi adalah kebiasaan atau istiadat.

Tapi tidak semua tradisi yang ada di masyarakat selamanya bisa langsung diwariskann dan diterima oleh generasi selanjutnya. Perlu adanya kerjasama antara generasi sebelumnya dan generasi selanjutnya untuk proses pewarisan tradisi. Salah satu bentuk kerjasama tersebut bisa dengan cara pertunjukan, pelatihan, atau dengan cara merevitalisasi bentuk tradisi, misalnya bentuk upacara seren tahun.

Tapi yang diwariskan dalam hal ini bukan bentuk dan tatacaranya saja, fungsi, kedudukan, dan nilai-nilai yang terkandung dalam tradisi tersebut harus diwariskan pula. Kegiatan tersebut selanjutnya jadi identitas masyarakat tersebut atau dalam istilah keilmuan tradisi disebut kearifan lokal.

Secara derivasional, istilah kearifan lokal (local wisdom) mencakup dua kata, yaitu kearifan (wisdom) dan lokal (local). Kata kearifan memiliki arti kebijaksanaan, sedangkan kata lokal artinya setempat. Melihat arti leksikal maka secara harfiah kearifan lokal (local wisdom) bisa diartikan gagasan-gagasan dan pengetahuan setempat yang bersifat bijaksana, penuh kearifan, bernilai baik, dan berbudi luhur yang dimiliki, dipedomani, dan dilaksanakan oleh anggota masyarakatnya.

Kearifan lokal merupakan kandungan tradisi lisan yang secara turun temurun diwarisi dan dimanfaatkan untuk menata kehidupan sosial masyarakat dalam segala bidang kehidupannya atau untuk 
mengatur tatanan kehidupan komunitas (Sibarani, 2012, hal. 112-113).

Sibarani (2012, hlm. 112), menambahkan bahwa kearifan lokal adalah nilai budaya lokal yang dapat dimanfaatkan untuk mengatur tatanan kehidupan masyarakat secara arif atau bijaksana. Kebijaksanaan atau pengetahuan asli suatu masyarakat yang berasal dari nilai luhur tradisi budaya untuk mengatur tatanan kehidupan masyarakat.

Karena itu nilai-nilai luhur dari sebuah masyarakat bisa dijadikan sumber penting dalam membentuk karakter generasi muda dalam menciptakan kedamaian dan meningkatkan kesejahteraan rakyat demi masa depan bangsa yang bermartabat dan makmur, serta memiliki ketahanan nilai budaya agar terhindar dari segala bentuk provokasi, demikian menurut (Sibarani 2012 hlm. 92-93). Salah satunya bisa dengan pemaknaan terhadap bentuk tradisi Seren Taun Guru Bumi, yang ada di masyarakat Sindang Barang, Kabupaten Bogor.

Seren Tahun Guru Bumi (STGB), merupakan tradisi yang dilakukan sebagai rasa sukur akan hasil pertanian di masyarakat Sindang Barang. Tradisi ini dilaksanakan setiap tahun. Pelaksanaannya sendiri berlangsung selama seminggu, dari tanggal 1-7 Muharam atau bertepatan dengan tanggal 2-8 Oktober 2016.

Jika melihat pada pelaksanaannya tradisi STGB memiliki maksud, fungsi, dan nilai-nilai yang terkandung didalamnya. Nilai-nilai tersebut tentu bermanfaat untuk kehidupan masyarakat, terutama dalam dunia pendidikan. Dalam dunia pendidikan banyak cara yang dilakukan untuk mengenalkan atau menyampaikan nilai-nilai mengenai tradisi masyarakat Sunda, khusunya mengenai tradisi seren tahun yang masih hidup di masyarakat. Salah satunya yaitu melalui pembelajaran membaca bahasan budaya di sekolah.
Dalam dunia pendidikan, pembelajaran membaca budaya penting dilakukan, hal ini berkaitan dengan pengenalan akan makna yang terdapat dalam bentuk budaya masyarakat Sunda, khususnya bentuk upacara seren tahun. Dalam KIKD disebutkan bahwa membaca wacana budaya merupakan salah satu bahan pembelajaran yang dijadikan pembelajaran membaca wacana di sekolah, khususnya untuk siswa di SMA kelas XI. Kurikulum tersebut bisa diterapkan dalam pelaksanaan kegiatan belajar-mengajar di kelas. Dalam arti guru harus bisa memilih dan menentukan bahan pengajaran teks bacaan wacana budaya untuk menarik minat siswa pada pembelajaran membaca di sekolah.

Tapi untuk menyampaikan nilai-nilai tersebut, perlu ditelaah dulu isi dari tradisi tersebut. Nilai-nilai tersebut bisa ditelaah dari pelaksanaan ritualnya dan tanda-tanda yang tampak dalam sepanjang tradisi STGB. Tanda-tanda tersbut bisa dilihat dari bentuk acara dan juga benda yang digunakan. Tapi untuk mencari hal itu, tentu diperlukan suatu pendekatan yang berhubungan dengan ilmu tanda. Dan dalam hal ini pendekatan semiotik yang paling cocok untuk digunakan, sebab keilmuan yang bertugas mengungkab masalah tanda yaitu semiotik. Adapun teori semiotik yang digunakan dalam tulisan ini adalah semiotik Carles S. Pierce.

\section{METODE}

Penelitian ini menggunakan pendekatan kualitatif, oleh karena itu metode yang digunakan dalam penelitian ini yaitu metode deskriptif analitik. Adapun metode asalnya dari bahasa Latin yaitu methodos yang artinya cara-cara, strategi untuk memahami realitas, langkah-langkah sistematis dalam menyelesaikan rangkaian sabab-akibat. Metode juga memiliki fungsi untuk menyelesaikan masalah dalam penelitian (Ratna, 2012, hal. 34). 
Dipilihnya metode deskriptif analitik sebab cara kerjanya yang menggambarkan dan menelaah tentang fakta-fakta yang ada dalam objek penelitian (Ratna, 2012, hal 53). Adapun yang disebut fakta-fakta dalam penelitian ini, adalah data tentang bentuk dan pelaksanaan, unsur semiotik, dan bagaimana aplikasi tradisi STGB di masyarakat Sindang Barang untuk bahan pembelajaran membaca wacana budaya. Sedangkan teknik penelitian yang digunakan adalah teknik studi pustaka.

\section{HASIL DAN PEMBAHASAN Kegiatan Pelaksanaan Tradisi Seren Tahun Guru Bumi}

STGB, merupakan tradisi untuk menunjukan rasa syukur atas hasil panen yang dihasilkan oleh masyarakat Sindang Barang. Tradisi ini dilaksanakan setiap tahun pada bulan Muharam selama satu minggu.

Tanggal pelaksanaannya tidak ditentukan oleh sesepuh, melainkan ditentukan oleh ketua kampung budaya melalui ilapat. Setelah ilapat didapatkan, ketua memberitakan kepada para sesepuh agar melaksanakan sérén taun. Ilapat biasanya datang dua bulan sebelum waktu pelaksanaan. Pada tahun 2016 sérén taun dilaksanakan tanggal 1-7 Muharam atau tanggal 2-8 Oktober 2016.

Menurut keterangan Bapa Maki ${ }^{1}$, rangkaian tradisi STGB di Kampung Sindang Barang berbeda dengan tradisi sérén taun di kampung-kampung lainnya. Perbedaan ini misalnya terletak pada waktu pelaksanaanya yang terjadi satu tahun sekali di bulan Muharam. Pelaksanaan kegiatan ini juga sekaligus memperingati tahun baru Islam. Selain itu bentuk acaranyapun berbeda. Acara yang dilaksanakan selama satu minggu itu dipenuhi oleh bermacam-macam tradisi dan kegiatan yang berjumlah sembilan kegiatan yaitu:

\footnotetext{
${ }^{1}$ Wawancara langsung dengan ketua Kampung Budaya Sindang Barang.
}

Sedekah Ngadiukkeun. Sedekah ngadiukkeun merupakan lawang sakéténg dalam sérén taun. Inti dari sedekah ngadiukkeun adalah tawasulan atau meminta ijin kepada Tuhan Yang Maha Suci bahwa di Kampung Sindang Barang akan diadakan upacara sérén taun.

Ngembang Makam Karuhun. Makam yang dituju diantaranya yaitu Gunung Salak, Pasir Karamat 3, Cileueur, Sirnagalih, dan Sindang Barang. Adanya tradisi ini bertujuan untuk menyampaikan rasa terima kasih kepada para nenek moyang dan meminta ijin kepadanya agar diperbolehkan mengadakan upacara sérén taun.

Sudat. Tradisi sudat merupakan sunatan masal. Tradisi ini sudah ada dari zaman dahulu. Salah satu cirinya terlihat dari masih dilaksanakannya tata cara disudat oleh béngkong dan atau prosesi membenamkan diri di sungai sebelum disudat. Tapi kekinian kebiasaan itu telah berubah. Béngkong telah diganti dengan dokter dan prosesi membenamkan diri di sungai telah diganti dengan penggunaan obat bius.

Munday atau marak. Tradisi munday merupakan tradisi menangkap(marak) secara bersama-sama di wahangan Sindang Barang atau di Cipamali. Tradisi marak sudah ada dari jaman dahulu yaitu zaman kerajaan. Pada zaman itu yang melakukan tradisi ini adalah rakyat dan raja. Tradisi ini diadakan selain untuk merekatkan tali persaudaraan, juga bertujuan untuk saling mengahargai status sosial yang ada di dalam masyarakat. Dengan cara bersamasama menangkap ikan, raja dan rakyat merupakan manusia yang harus samasama merasakan basah di sungai. Udahan seperti ini masih berlaku sampai sekarang.

Ngala Cai Kukulu. Tradisi ngala cai kukulu dilakukan pada tujuh sumber mata air. Sumber-sumber matai air itu yaitu, Cipamali, Cilipah, Cikubang, Jalatunda, Cieming, Ciéja, jeung Ciputri. Maksud 
dari ngala cai kukulu sebenarnya untuk kepentingan upacara lainnya.

Ngahijikeun Cai Kukulu. Air yang dikumpulkan dari tujuh mata air itu kemudian disatukan dalam buyung. Proses penyatuannya sama seperti pada umumnya. Para sesepuh yang telah mendapatkan airnya secara bergantian menyalurkan air itu ke dalam buyung. Hal yang tidak biasa muncul pada waktu malam harinya. Air yang telah disatukan itu disimpan ditengah kerumunan sambil ditawasulkan dan dibacakan kitab suci Al-Qur'an secara bersamaan dipimpin oleh Hulunjati.

Sedekah Kuéh. Kue yang disedekahkan adalah hasil sumbangan warga yang dikumpulkan di alun-alun kampung budaya. Berdasarkan aturannya, jenis kue yang disumbangkan harus berjumlah tujuh jenis. Sedangkan bentuknya dipasrahkan kepada warga, yang penting jenis kue itu berjumlah 7 jenis dan merupakan kue-kue khas jaman dahulu. Tujuannya hanya untuk sedekah tanpa ada sedikitpun ada tujuan mistis. Tapi, cara sedekahnya yang berbeda yaitu dengan cara diperebutkan setelah diciprati oleh air kukulu dan ditawasuli oleh hulunjati.

Nugel Munding. Tradisi nugel munding setelah tradisi sedekah kue selesai dilaksanakan. Tujuan dari tradisi ini sama dengan tradisi sedekah kue yaitu sedekah. Yang menyebabkan munding ditugel adalah karena daging munding dibagikan kepada warga. Dalam tradisi nugel munding tidak ada aturan jumlah kernau yang ditugelna, lebih banyak lebih bagus.

Helaran Dongdang. Helaran dongdang adalah tradisi pamungkas dan puncak dalam pergelaranan Tradisi STGB. Dongdag merupakan medium atau tempat untuk menyimpan hasil pertanian yang seterusnya diiringkan kearah alun-alun kampung budaya. Yang diiringkan tidak hanya dongdang saja, tapi juga padi yang diangkut dalam bentuk rengkong. Tapi dalam tradisi ini padi yang dibawa dimasukan ke dalam leuit, sedangkan hasil pertanian lain yang berada di atas dongdang deperebutkan oleh warga.

\section{Nilai Semiotik dalam Tradisi $S T G B$}

Pierce membagi semiotik menjadi trikotomi tanda, yaitu(1) hubungan antara penanda dan warna tandannya (qualisign, sinsign, dan legisign); (2) hubungan antara kenyataan dengan warna dasarnya (ikon, indeks, dan simbol); dan (3) hubungan antara pikiran dengan bentuk pernandanya (rheme or seme, dicent or dicisign or pheme, dan argument) (Santosa, 1993, hal. 10; lht. Syuropati, 2003, hal. 69-70; lht Budiman, 2011, hal. 23-25). Meski begitu, penelitian ini hanya menggunakan salah satu diantara trikotomi yaitu bagian kedua hubungan antara kenyataan dan warna dasarnya yang terdiri dari: ikon, indeks dan simbol.

\section{Ikon}

Ikon yang muncul dalam tradisi ini diantaranya yaitu padi. Padi tidak hanya terkait dengan hasil pertanian dan komoditas utama masyarakat Sunda dalam rangka mempertahankan hidupnya. Tapi lebih dalam lagi, merupakan sejarah panjang bahkan merupakan salah satu mitos yang sakral. Mitos ini berkaitan dengan Dewi Sri atau Nyi Pohaci. Karenanya padi terbilang sangat dijaga. Karena merupakan benda yang bisa mempertahankan hidup manusia.

Selain dari hasil pertanian, ikon dalam tradisi STGB yang terlihat pada setiap rangkaian kegiatan tradisi STGB diantaranya yaitu kembang, kue, air, ikan, kerbau dan dongdang.

\section{Indeks}

Indeks yang ditemukan dalam tradisi ini yaitu tradisi seren taun-nya sendiri. Penyebab dari adanya tradisi seren taun adalah adalah rasa syukur masyarakat atas hasil pertanian. Rasa syukur ditunjukan dengan cara syukuran (sedekah) bersama-sama. Hal ini terlihat 
dari rangkaian dan pelaksanaannya seperti sedekah kue, nugel munding dan arak-rarakan dongdang yang pada dasarnya merupakan sedekah. Karena, apa yang dikumpulkan merupakan persembahan masyarakat untuk kegaiban.

Memang, beberapa diantaranya dilakukan dengan cara diperebutkan seperti pada sedekah kue dan arak-arakan gondang. Tapi, yang menjadi tujuan dari kegiatan ini sama sekali tidak terkait dengan aspek sakral melainkan aspek sosialnya:

kebersamaannya memprebutkan hasil pertanian. Adapun ada hal-hal yang tidak diperbolehkan, hal-hal itu tidak berdampak atau tidak memiliki akibat.

Selain sérén taun, yang menjadi indeks dalam tradisi ini diantaranya yaitu sedekah ngadiukkeun, ngembang makam karuhun, ngala cai kukulu, ngahijikeun cai kukulu, sedekah kuéh, munday, nugel munding dan helaran dongdang. Adanya macam-macam bentuk kagiatan di atas disebabkan adanya tradisi sérén taun. Jelasnya tidak akan ada kegiatan seperti sedekah ngadiukkeun, ngala cai kukulu, dan yang lainnya jika tidak ada tradisi STGB.

\section{Simbol}

Simbol yang ditemukan dalam tradisi ini diantaranya yaitu padi, air kukulu, air tujuh rupa, kembang tujuh rupa, kuéh tujuh rupa, Ayam bakar, menyan, parukuyan, buyung, dongdang, marak lauk, nugel munding, jeung majikeun paré.

1. Padi merupakan simbol kesejahteraan

2. Air kukulu merupakan simbol dari kehidupan manusia. Selain itu, Air juga merupakan simbol dari kesucian.

Karena, fungsinya yang bisa membersihkan segala kotoran baik yang bersifat lahiriah ataupun batiniah.

3. Air tujuh rupa merupakan simbol dari kehidupan manusia. Begitupun Air tujuh rupa dalam tradisi STGB yang menjadi simbol bahwa di dalam perjalanan hidup didunia ada pahit dan manis yang harus dilewati.

4. Kembang tujuh rupa merupakan simbol kehidupan dan atau harapan. Hal ini bisa tercium dari baunya yang wangi dan penampakannya yang segar menandakan adanya kehidupan baru atau harapan. Dalam konteks tradisi STGB, kembang digunakan dalam tradisi ngembang makam karuhun. Hal ini dimaksudkan agar wewangian nenek moyang akan terus tercium dan tidak pernah hilang. Dalam hal ini bisa terlihat bahwa gernerasi selanjutnya agar jangan sampai melupakan nenek moyang yang sebelumnya telah mengharumkan dunia. Selain itu, pemberi kembang juga agar sadar bahwa kehidupan tidak hanya sampai didunia, tapi ada kehidupan selanjutnya yaitu alam ahirat.

5. Kue tujuh rupa simbol dari silaturahmi. Berdasarkan konteksnya keu digunakan pada waktu tradisi sedekah kue yang diperebutkan oleh warga. Dari hal ini dapat terlihat bahwa selain untuk sedekah kepada warga, kue juga menjadi tanda hubungan silaturahmi antar warga. Saling bersentuhannya tangan warga saat memperebutkan kue menjadi tanda bahwa kue adalah simbol silaturahmi.

6. Bakakak hayam (ayam bakar) merupakan simbol dari rasa pasrah atas segala hal yang ditentukan oleh Tuhan Yang Maha Kuasa sambil tetap terus bermunajat kepadanya. Pasrah dalam hal ini bukan berarti memasrahkan begitu saja, tapi sambil diiringi dengan ikhtiar dan doa kepada Yang Kuasa. Begitu juga dalam tradisi ini. Kelengkapan bakakak hayam ada ketika tradisi ngadiukeun lumangsung. Maksud dari tradisi ini meminta kepada Tuhan Yang Maha Suci agar kebutuhan untuk upacara seren taun bisa terpenuhi, tidak lebih tidak kurang. 
7. Menyan mencirikan kebul kita, yaitu hati dan keinginan kita sebagai manusia kepada Yang Maha Suci yang juga disebut Putih.Sedangkan merah murpakan simbol hati manusia yang berdoa dan pasrah kepada Tuhan Yang Maha Suci yaitu Allah SWT.

8. Parukuyan merupakan wadah tempat menyan atau disimbolkan juga menjadi raga besar, badan atau yang mewadahi hati.

9. Buyung merupakan wadah atau tempat menyimpan air kukulu. Buyung merupakan simbol yang menyatukan tujuh kehidupan dan penghubung antara macam-macam kehidupan yang disimbolkan dari masing-masing mata air.

10. Dongdang merupakan simbol bahwa segala nikmat yang telah diberikan kepada manusia harus dijaga. Baik itu berwujud hasil bumi, kesehatan, keluarga dll. Sedangkan simbol dari dongdang terlihat jelas dari bentuknya. Bentuk dongdang menyerupai atap rumah dan didalamnya penuh dengan hasil bumi yang dihias sampai terlihat indah. Telain dari bentuknya, dongdang dibawa dengan cara digotong. Hal ini memiliki nilai sosial yang tinggi yaitu manusia di segala beidang harus membiasakan hidup gotong royong.

11. Marak Lauk simbol dari identitas manusia. Yang berarti dalam kehidupan di alam dunia, semua manusia sama tak ada bedanya. Baik itu raja, rakyat maupun pejabat, semuanya menjadi kotor ketika menjalani kehidupan.

12. Munding merupakan simbol dari dunia langit dimana tempat berka diturunkan. Jadi, sejak awal telah ditentukan bahwa hewan yang akan dipakai dalam tradisi ini adalah munding. Selain itu melihat pada konteks masyarakat sunda yang agraris (ngahuma), hewan yang dipakai untuk ngawuluku adalah munding. Serta sebab masyarakat pada waktu banyak yang memiliki huma, maka banyak pula yang mempunyai munding. Akhirnya mundinglah yang menjad hewasn sedekah.

13. Majikeun Paré disebut juga dengan mengawinkan padi. Maksudnya padi yang dimasukan agar mendapatkan benih padi yang bagus untuk pertanian selanjutnya hasilnya melimpah.

\section{SIMPULAN}

Sebagaimana yang terlihat dalam tradisi STGB, ada beberapa praktek yang berbeda. Salah satu contohnya dalam penentuan tanggal pelaksanaan tradisi STGB yang harus menanti ilapat yang datang kepada ketua kampung budaya. Biasanya ilapat ini datang melalui mimpi. Apabila ilapat tidak datang, plaksanaan tradisi sérén taun harus ditunda terlebih dahulu.

Selain itu perubahan juga terlihat pada proses pelaksanaannya. Yang sebelumnya dilaksanakan oleh masingmasing kampung, kini dilaksanakan bersama-sama secara kolosal. Tapi ruh dari tradisi ini tetap merujuk pada STGB yang sampai sekarang masih eksis di beberapa kampung adat yang ada di wilayah Jawa Barat dan Banten.

Sebagai penutup, adanya penelitian tentang tradisi sérén taun sebenarnya ditujukan untuk membangkitkan kembali dan membangun kesadaran bahwa tradisi itu tidak statis. Unsur-unsurnya selalu berubah sering dengan perkembangan zaman, tapi hakikatnya tetap sama. Hal ini dilakukan untuk terus mengucapakan rasa syukur kepada Tuhan Yang Maha Kuasa atas apa yang sudah dihasilkan dan dimamfaatkan oleh mahluknya dari alam sekitarnya.. selain itu, kepentingan adanya studi tradisi sérén taun bertujuan untuk memperkenalkan tradisi Sunda khususnya sérén taun dan menyampaikan makna yang berada di dalamnya. khususnya dalam bidang pendidikan, bisa 
dijadikan bahan pembelajaran membaca sampai pada menumbuhkan minat murid untuk melestarikan tradisi Sunda.

\section{DAFTAR PUSTAKA}

Budiman, K. (2011). Semiotoka Visual: Konsep, Isu, dan Problem Ikonisitas. Yogyakarta: Jalasutra.

Danadibrata, R. A. (2006). Kamus Basa Sunda. Bandung: Kiblat Buku Utama jeung UNPAD.

Koentjaraningrat. (1985). Kebudayaan, Mentalitas, dan Pembangunan. Jakarta: Gramedia Pustaka Utama.

Ratna, N. K. (2012). Teori, Metode, dan Teknik Penelitian Sastra. Yogyakarta: Pustaka Pelajar.
Sibarani, R. (2012). Kearifan Lokal; Hakikat, Peran, dan Métode Tradisi Lisan. Jakarta: Asosiasi Tradisi Lisan.

Santosa, P. (1993). Ancangan Semiotika dan Pengkajian Susastra. Bandung: Angkasa.

Syuropati, M. A. (2003). Teori Sastra Kontemporer dan 13 Tokohnya. Yogyakarta: In Azna Book.

\section{UCAPAN TERIMA KASIH}

Terima kasih penulis sampaikan kepada semua pihak yang telah membantu penelitian ini, terutama kepada Penyunting Jurnal Lokabasa atas dimuatnya tulisan ini. 